\title{
Erratum to: Role of complexity of variant Philadelphia chromosome in chronic myeloid leukemia in the era of tyrosine kinase inhibitor therapy
}

\author{
Zimu Gong ${ }^{1,2} \cdot$ Lan Zheng ${ }^{1} \cdot$ Zhenya Tang $^{1} \cdot$ Zi Chen $^{1} \cdot$ Wei Wang ${ }^{1} \cdot$ Shi Bai $^{1}$ • \\ Guilin Tang ${ }^{1} \cdot$ L. Jeffrey Medeiros ${ }^{1} \cdot$ Shimin $\mathrm{Hu}^{1}$
}

Published online: 20 May 2017

(C) Springer-Verlag Berlin Heidelberg 2017

Erratum to: Annals of Hematology 96(3): 501-504

DOI 10.1007/s00277-016-2892-7

The name of L. Jeffrey Medeiros was incorrectly tagged in the original version of this article. L. Jeffrey should be the author name and Medeiros is the family name. With this, it should be presented as Medeiros LJ.

The online version of the original article can be found at http://dx.doi.org/ $10.1007 / \mathrm{s} 00277-016-2892-7$

$\triangle$ Shimin $\mathrm{Hu}$

shu1@mdanderson.org

1 Department of Hematopathology, University of Texas MD Anderson Cancer Center, Houston, TX 77030, USA

2 Department of Hematology, Shengjing Hospital of China Medical University, Shenyang, China 